\title{
On the error estimation and T-stability of the Ishikawa iteration for strongly demicontractive mappings
}

\author{
Chao Wang ${ }^{1 *}$, Xueli Li and Pengkun Huang ${ }^{2}$
}

\section{"Correspondence:}

wangchaosx@126.com

${ }^{1}$ School of Mathematics and

Statistics, Nanjing University of

Information Science and

Technology, Nanjing, P.R. China

Full list of author information is

available at the end of the article

\section{Springer}

\begin{abstract}
In this paper, some new formula of error estimations of Ishikawa iteration and some strong convergence theorems of strongly demicontractive mappings are first obtained. And then, convergence speeds and error estimations of the Ishikawa iteration and the Mann iteration are discussed in some examples. Finally, T-stability of the Ishikawa iteration is proved.

MSC: $47 \mathrm{H} 09 ; 47 \mathrm{H} 10$

Keywords: Error estimation; Ishikawa iteration; Mann iteration; Strongly demicontractive mappings; T-stability
\end{abstract}

\section{Introduction and preliminaries}

Let $(X,\|\cdot\|)$ be a real Hilbert space and $C$ be a closed convex subset of $X$. Let $T: C \rightarrow C$ and $\operatorname{Fix}(T)$ denotes the set of fixed points of $T$, that is, $\operatorname{Fix}(T)=\{x \in C: T x=x\}$. A sequence $\left\{x_{n}\right\}$ is called the Ishikawa iteration of $T$ if, for an arbitrary $x_{0} \in C$,

$$
\left\{\begin{array}{l}
x_{n+1}=\left(1-\alpha_{n}\right) x_{n}+\alpha_{n} T y_{n}, \\
y_{n}=\left(1-\beta_{n}\right) x_{n}+\beta_{n} T x_{n},
\end{array}\right.
$$

where $\alpha_{n}, \beta_{n} \in[0,1]$ and $n \geq 0$. We know that if $\beta_{n}=0$, then the Ishikawa iteration is called the Mann iteration. Error estimations of the Mann iteration for some contractive and nonexpansive type mappings have been studied in [1-3]. In 2015, L. Maruster and St. Maruster [4] gave the notation of a strongly demicontractive mapping as follows:

The mapping $T$ is called strongly demicontractive if $\operatorname{Fix}(T) \neq \emptyset$ and

$$
\left\|T x-x^{*}\right\|^{2} \leq a\left\|x-x^{*}\right\|^{2}+K\|T x-x\|^{2}
$$

for all $x \in C, x^{*} \in \operatorname{Fix}(T)$, where $a \in(0,1)$ and $K \geq 0$. (It is easy to see that if $T$ is a strongly demicontractive mapping, then the fixed point of $T$ is unique.) And then, they considered an error estimation of the Mann iteration and the strong convergence for strongly demicontractive mappings. T-stability of the Mann iteration for a particular case of strongly demicontractive mapping was also proved. Later, $[5,6]$ provided some other convergence

(c) The Author(s) 2019. This article is distributed under the terms of the Creative Commons Attribution 4.0 International License (http://creativecommons.org/licenses/by/4.0/), which permits unrestricted use, distribution, and reproduction in any medium, provided you give appropriate credit to the original author(s) and the source, provide a link to the Creative Commons license, and indicate if changes were made. 
theorems of the Mann iteration for strongly demicontractive mappings. The problem of T-stability for some iterations was discussed in $[7,8]$. Recently, comparative studies on some iterations (including the Mann iteration and the Ishikawa iteration) for contractive maps have been reported (see $[9,10])$.

By using the idea of $[4,6,9]$, we first introduce some new formula of error estimations of Ishikawa iteration and prove some convergence theorems of Ishikawa iteration for strongly demicontractive mappings, and then some examples are given to compare Ishikawa iteration (1.1) with the Mann iteration. Moreover, we will also discuss T-stability of the Ishikawa iteration for strongly demicontractive mappings.

We now show some lemmas to be used in the main result.

Lemma 1.1 ([2, 4]) Let $\left\{d_{n}\right\},\left\{\epsilon_{n}\right\}$ be nonnegative sequences of real numbers satisfying

$$
d_{n+1} \leq \alpha d_{n}+\epsilon_{n}
$$

for all $n \geq 0$ and $0 \leq \alpha<1$. If $\lim _{n \rightarrow \infty} \epsilon_{n}=0$, then $\lim _{n \rightarrow \infty} d_{n}=0$.

Lemma 1.2 ([4]) Let $\left\{d_{n}\right\}$ be a nonnegative sequence satisfying

$$
d_{n+1} \leq \alpha d_{n}+\beta \epsilon_{n}
$$

where $0<\alpha<1, \beta>0$ and $\left\{\epsilon_{n}\right\}$ is a nonnegative sequence that satisfies the condition

$$
\frac{\epsilon_{n+1}}{\epsilon_{n}} \geq 2 \alpha, \quad \forall n \in \mathbb{N}
$$

Then

$$
d_{n+1} \leq d_{0} \alpha^{n+1}+\beta\left(2 \alpha \epsilon_{n-1}+\epsilon_{n}\right) .
$$

Motivated by the above lemma, Wang [6] gave the following lemma (which gives a fast convergence condition of $d_{n}$ ).

Lemma 1.3 ([6]) Let $\left\{d_{n}\right\}$ be a nonnegative sequence satisfying (1.3), where $0<\alpha<1, \beta>0$ and $\left\{\epsilon_{n}\right\}$ is a nonnegative sequence that satisfies the condition

$$
\frac{\epsilon_{n+1}}{\epsilon_{n}} \leq \frac{\alpha}{2}, \quad \forall n \in \mathbb{N} .
$$

Then $\lim _{n \rightarrow \infty} d_{n}=0$ and

$$
d_{n+1} \leq d_{0} \alpha^{n+1}+\beta\left(\alpha^{n} \epsilon_{0}+2 \alpha^{n-1} \epsilon_{1}\right) .
$$

\section{Error estimations of the Ishikawa iteration for strongly demicontractive mappings}

In this section, we mainly give two formulas of error estimations of the Ishikawa iteration, and some convergence theorems are also obtained. 
Theorem 2.1 Let $T$ be L-Lipschitzian (that is, there exists $L>0$ such that $\|T x-T y\| \leq$ $L\|x-y\|$ for any $x, y \in C)$ and strongly demicontractive with $0<a<1$ and $K \geq 0, x^{*} \in$ $\operatorname{Fix}(T)$. Assume that there exist positive numbers $\theta_{1}, \theta_{2}, 0<\theta_{1}<\theta_{2}<\min \{1,1-(1-a)(1-$ K)\} such that

$$
\frac{\left\|T T_{\alpha_{n}, \beta_{n}} x-T_{\alpha_{n}, \beta_{n}} x\right\|^{2}}{\|T x-x\|^{2}} \geq 2 \theta_{2},
$$

where $x \in K$ and $T_{\alpha_{n}, \beta_{n}}:=\left(1-\alpha_{n}\right) I+\alpha_{n} T_{\beta_{n}}, T_{\beta_{n}}:=\left(1-\beta_{n}\right) I+\beta_{n} T$. For $x_{0} \in C$, let $\left\{x_{n}\right\}$ be the sequence generated by Ishikawa iteration (1.1) with the control sequences $\left\{\alpha_{n}\right\}$ and $\left\{\beta_{n}\right\}$ satisfying

$$
\begin{aligned}
& \frac{1-\theta_{2}}{1-a} \leq \alpha_{n} \leq \frac{1-\theta_{1}}{1-a}, \\
& 0 \leq \beta_{n} \leq q<1, \quad L^{2} q^{2}+q+a<1,
\end{aligned}
$$

for some $0 \leq q<1$. Then the following error estimation for the sequence $\left\{x_{n}\right\}$ holds:

$$
\left\|x_{n+1}-x^{*}\right\|^{2} \leq\left\|x_{0}-x^{*}\right\|^{2} \theta_{2}^{n+1}+(1+L q)^{2} M\left(2 \theta_{2} \epsilon_{n-1}+\epsilon_{n}\right),
$$

where $M=\left(\frac{1-\theta_{1}}{1-a}\right)^{2}-(1-K) \frac{1-\theta_{1}}{1-a}$ and $\epsilon_{n}=\left\|T x_{n}-x_{n}\right\|^{2}$.

Proof From $T$ is a strongly demicontractive mapping in the Hilbert space $X$, we have

$$
\begin{aligned}
\left\|x_{n+1}-x^{*}\right\|^{2} & =\left\|\left(1-\alpha_{n}\right) x_{n}+\alpha_{n} T y_{n}-x^{*}\right\|^{2} \\
& =\left\|\left(1-\alpha_{n}\right)\left(x_{n}-x^{*}\right)+\alpha_{n}\left(T y_{n}-x^{*}\right)\right\|^{2} \\
& =\left(1-\alpha_{n}\right)\left\|x_{n}-x^{*}\right\|^{2}+\alpha_{n}\left\|T y_{n}-x^{*}\right\|^{2}-\alpha_{n}\left(1-\alpha_{n}\right)\left\|T y_{n}-x_{n}\right\|^{2} .
\end{aligned}
$$

Since

$$
\begin{aligned}
\left\|T y_{n}-x^{*}\right\|^{2} \leq & a\left\|y_{n}-x^{*}\right\|^{2}+K\left\|y_{n}-T y_{n}\right\|^{2} \\
= & a\left\|\left(1-\beta_{n}\right)\left(x_{n}-x^{*}\right)+\beta_{n}\left(T x_{n}-x^{*}\right)\right\|^{2}+K \|\left(1-\beta_{n}\right)\left(x_{n}-T y_{n}\right) \\
& +\beta_{n}\left(T x_{n}-T y_{n}\right) \|^{2} \\
\leq & a\left[\left(1-\beta_{n}\right)\left\|x_{n}-x^{*}\right\|^{2}+\beta_{n}\left\|T x_{n}-x^{*}\right\|^{2}-\beta_{n}\left(1-\beta_{n}\right)\left\|T x_{n}-x_{n}\right\|^{2}\right] \\
& +K\left[\left(1-\beta_{n}\right)\left\|x_{n}-T y_{n}\right\|^{2}+\beta_{n}\left\|T x_{n}-T y_{n}\right\|^{2}-\beta_{n}\left(1-\beta_{n}\right)\left\|T x_{n}-x_{n}\right\|^{2}\right] \\
\leq & a\left(1-\beta_{n}\right)\left\|x_{n}-x^{*}\right\|^{2}+a \beta_{n}\left\|T x_{n}-x^{*}\right\|^{2}-\left[a \beta_{n}\left(1-\beta_{n}\right)\right. \\
& \left.\left.+K \beta_{n}\left(1-\beta_{n}\right)\right]\left\|T x_{n}-x_{n}\right\|^{2}\right]+K\left(1-\beta_{n}\right)\left\|x_{n}-T y_{n}\right\|^{2} \\
& +K \beta_{n}\left\|T x_{n}-T y_{n}\right\|^{2} \\
\leq & a\left(1-\beta_{n}\right)\left\|x_{n}-x^{*}\right\|^{2}+a \beta_{n}\left[a\left\|x_{n}-x^{*}\right\|^{2}+K\left\|x_{n}-T x_{n}\right\|^{2}\right]-\left[a \beta_{n}\left(1-\beta_{n}\right)\right. \\
& \left.\left.+K \beta_{n}\left(1-\beta_{n}\right)\right]\left\|T x_{n}-x_{n}\right\|^{2}\right]+K\left(1-\beta_{n}\right)\left\|x_{n}-T y_{n}\right\|^{2} \\
& +K \beta_{n}\left\|T x_{n}-T y_{n}\right\|^{2} \\
\leq & a\left(1-\beta_{n}+a \beta_{n}\right)\left\|x_{n}-x^{*}\right\|^{2}+\left[a K \beta_{n}-(a+K) \beta_{n}\left(1-\beta_{n}\right)\right]\left\|x_{n}-T x_{n}\right\|^{2} \\
& +K\left(1-\beta_{n}\right)\left\|x_{n}-T y_{n}\right\|^{2}+K \beta_{n}\left\|T x_{n}-T y_{n}\right\|^{2},
\end{aligned}
$$


we can get that

$$
\begin{aligned}
\left\|x_{n+1}-x^{*}\right\|^{2} & \\
\leq & {\left[1-\alpha_{n}+\alpha_{n} a\left(1-\beta_{n}+a \beta_{n}\right)\right]\left\|x_{n}-x^{*}\right\|^{2}+\alpha_{n}\left[a K \beta_{n}-(a+K) \beta_{n}\left(1-\beta_{n}\right)\right] } \\
& \cdot\left\|T x_{n}-x_{n}\right\|^{2}+K \alpha_{n} \beta_{n}\left\|T x_{n}-T y_{n}\right\|^{2}+\alpha_{n}\left[K\left(1-\beta_{n}\right)-1+\alpha_{n}\right]\left\|x_{n}-T y_{n}\right\|^{2} .
\end{aligned}
$$

Since $T$ is L-Lipschitzian, we have

$$
\left\|T x_{n}-T y_{n}\right\| \leq L\left\|x_{n}-y_{n}\right\| \leq L \beta_{n}\left\|x_{n}-T x_{n}\right\|
$$

and

$$
\left\|T y_{n}-x_{n}\right\| \leq\left\|T y_{n}-T x_{n}+T x_{n}-x_{n}\right\| \leq\left(1+L \beta_{n}\right)\left\|x_{n}-T x_{n}\right\| .
$$

Using the inequality $(*),(2.5)$, and (2.6), we obtain

$$
\begin{aligned}
\left\|x_{n+1}-x^{*}\right\|^{2} \leq & {\left[1-\alpha_{n}+\alpha_{n} a\left(1-\beta_{n}+a \beta_{n}\right)\right]\left\|x_{n}-x^{*}\right\|^{2}+\alpha_{n} \beta_{n}\left[a K-(a+K)\left(1-\beta_{n}\right)\right.} \\
& \left.+K L^{2} \beta_{n}^{2}\right]\left\|T x_{n}-x_{n}\right\|^{2}+\alpha_{n}\left[K\left(1-\beta_{n}\right)-1+\alpha_{n}\right]\left(1+L \beta_{n}\right)^{2}\left\|x_{n}-T x_{n}\right\|^{2} .
\end{aligned}
$$

Using (2.3), we get

$$
\begin{aligned}
\left\|x_{n+1}-x^{*}\right\|^{2} \leq & {\left[1-\alpha_{n}+\alpha_{n} a\left(1-\beta_{n}+a \beta_{n}\right)\right]\left\|x_{n}-x^{*}\right\|^{2}+\alpha_{n}\left[K\left(1-\beta_{n}\right)-1+\alpha_{n}\right] } \\
& \cdot\left(1+L \beta_{n}\right)^{2}\left\|x_{n}-T x_{n}\right\|^{2} \\
\leq & {\left[1-\alpha_{n}(1-a)\right]\left\|x_{n}-x^{*}\right\|^{2}+\left(1+L \beta_{n}\right)^{2}\left[\alpha_{n}^{2}-(1-K) \alpha_{n}\right]\left\|x_{n}-T x_{n}\right\|^{2} . }
\end{aligned}
$$

Similar to the proof of Theorem 1 in [4], we have

$$
\left\|x_{n+1}-x^{*}\right\|^{2} \leq \theta_{2}\left\|x_{0}-x^{*}\right\|^{2}+(1+L q)^{2} M \epsilon_{n}
$$

where $M=\left(\frac{1-\theta_{1}}{1-a}\right)^{2}-(1-K) \frac{1-\theta_{1}}{1-a}$ and $\epsilon_{n}=\left\|T x_{n}-x_{n}\right\|^{2}$. From Lemma 1.2, it follows that

$$
\left\|x_{n+1}-x^{*}\right\|^{2} \leq\left\|x_{0}-x^{*}\right\|^{2} \theta_{2}^{n+1}+(1+L q)^{2} M\left(2 \theta_{2} \epsilon_{n-1}+\epsilon_{n}\right) .
$$

Corollary 2.1 Suppose that $T$ satisfies all the conditions of Theorem 2.1 and it is also asymptotically T-regular, i.e., $\left\|T x_{n}-x_{n}\right\| \rightarrow 0$. Then the Ishikawa iteration $\left\{x_{n}\right\}$ with control sequence satisfying (2.2)-(2.3) converges strongly to $x^{*}$.

Remark 2.1 If $\beta_{n}=q=0$, then the Ishikawa iteration changes into the Mann iteration, which was considered in [4]. In this case, $y_{n} \equiv x_{n}$, from $(*)$, we know that

$$
\left\|x_{n+1}-x^{*}\right\|^{2} \leq\left[1-\alpha_{n}(1-a)\right]\left\|x_{n}-x^{*}\right\|^{2}+\left[\alpha_{n}^{2}-(1-K) \alpha_{n}\right]\left\|x_{n}-T x_{n}\right\|^{2} .
$$

Hence, Theorem 1 and Corollary 1 in [4] can be proved ( $T$ does not need to be LLipschitzian). 
By [6] and Lemma 1.3, we can also get the following theorem.

Theorem 2.2 Let $T$ be L-Lipschitzian and strongly demicontractive with $0<a<1$ and $K \geq 0, x^{*} \in \operatorname{Fix}(T)$. Assume that there exist positive numbers $\theta_{1}, \theta_{2}, 0<\theta_{1}<\theta_{2}<\min \{1,1-$ $(1-a)(1-K)\}$ such that

$$
\frac{\left\|T T_{\alpha_{n}, \beta_{n}} x-T_{\alpha_{n}, \beta_{n}} x\right\|^{2}}{\|T x-x\|^{2}} \leq \frac{\theta_{2}}{2}
$$

where $x \in K$ and $T_{\alpha_{n}, \beta_{n}}:=\left(1-\alpha_{n}\right) I+\alpha_{n} T_{\beta_{n}}, T_{\beta_{n}}:=\left(1-\beta_{n}\right) I+\beta_{n} T$. For $x_{0} \in C$, let $\left\{x_{n}\right\}$ be the sequence generated by Ishikawa iteration (1.1) with the control sequences $\left\{\alpha_{n}\right\}$ and $\left\{\beta_{n}\right\}$ satisfying

$$
\begin{aligned}
& \frac{1-\theta_{2}}{1-a} \leq \alpha_{n} \leq \frac{1-\theta_{1}}{1-a}, \\
& 0 \leq \beta_{n} \leq q<1, \quad L^{2} q^{2}+q+a<1,
\end{aligned}
$$

for some $0 \leq q<1$. Then $\left\{x_{n}\right\}$ converges strongly to the fixed point of $T$, and the following error estimation for the sequence $\left\{x_{n}\right\}$ holds:

$$
\left\|x_{n+1}-x^{*}\right\|^{2} \leq\left\|x_{0}-x^{*}\right\|^{2} \theta_{2}^{n+1}+(1+L q)^{2} M\left(\theta_{2}^{n} \epsilon_{0}+2 \theta_{2}^{n-1} \epsilon_{1}\right)
$$

where $M=\left(\frac{1-\theta_{1}}{1-a}\right)^{2}-(1-K) \frac{1-\theta_{1}}{1-a}$ and $\epsilon_{n}=\left\|T x_{n}-x_{n}\right\|^{2}$.

Proof From the proof of Theorem 2.1, we have

$$
\left\|x_{n+1}-x^{*}\right\|^{2} \leq \theta_{2}\left\|x_{0}-x^{*}\right\|^{2}+(1+L q)^{2} M \epsilon_{n}
$$

where $M=\left(\frac{1-\theta_{1}}{1-a}\right)^{2}-(1-K) \frac{1-\theta_{1}}{1-a}$ and $\epsilon_{n}=\left\|T x_{n}-x_{n}\right\|^{2}$. From Lemma 1.3, it follows that $\left\{x_{n}\right\}$ converges strongly to the fixed point of $T$ and

$$
\left\|x_{n+1}-x^{*}\right\|^{2} \leq\left\|x_{0}-x^{*}\right\|^{2} \theta_{2}^{n+1}+(1+L q)^{2} M\left(\theta_{2}^{n} \epsilon_{0}+2 \theta_{2}^{n-1} \epsilon_{1}\right) .
$$

Remark 2.2 If $\beta_{n}=0$, then the Ishikawa iteration changes into the Mann iteration considered in [6]. In this case, $q=0$. From (2.8), we know that

$$
\left\|x_{n+1}-x^{*}\right\|^{2} \leq\left\|x_{0}-x^{*}\right\|^{2} \theta_{2}^{n+1}+M\left(\theta_{2}^{n} \epsilon_{0}+2 \theta_{2}^{n-1} \epsilon_{1}\right) .
$$

Hence, Theorem 2.1 in [6] can proved ( $T$ does not need to be L-Lipschitzian).

Remark 2.3 It is worth mentioning that error estimation (2.8) of the Ishikawa iteration depends on $L, q, M, \theta_{2}, \epsilon_{0}$, and $\epsilon_{1}$. But if $n$ is large enough, then error estimation (2.8) depends only on $\theta_{2}$. Hence, error estimation (2.8) is better than error estimation (2.4) of the Ishikawa iteration. 


\section{The Ishikawa iteration and the Mann iteration for strongly demicontractive mappings in an example}

In fact, if $T$ has some particular properties, then the conditions of Theorem 2.2 can be satisfied. Suppose that $T: \mathbb{R} \rightarrow \mathbb{R}$ is a differentiable mapping, it is L-Lipschitzian and strongly demicontractive with $0<a<1, K \geq 0$. The sequence $\left\{x_{n}\right\}$ is generated by the Ishikawa iteration with control sequence satisfying

$$
\alpha_{n} \equiv t_{1}, \quad \beta_{n} \equiv t_{2}, \quad 0 \leq t_{2}<1, \quad L^{2} t_{2}^{2}+t_{2}+a<1 \quad \text { and } \quad \frac{1-\theta_{2}}{1-a} \leq t_{1} \leq \frac{1-\theta_{1}}{1-a} .
$$

In this case, we have

$$
\begin{aligned}
& T T_{t_{1}, t_{2}} x-T_{t_{1}, t_{2}} x \\
& \quad=T\left\{\left(1-t_{1}\right) x+t_{1}\left[\left(1-t_{2}\right) x+t_{2} T x\right]\right\}-\left\{\left(1-t_{1}\right) x+t_{1}\left[\left(1-t_{2}\right) x+t_{2} T x\right]\right\} \\
& \quad=T\left[x+t_{1} t_{2}(T x-x)\right]-T x+T x-x-t_{1} t_{2}(T x-x) \\
& \quad=t_{1} t_{2} T^{\prime} \xi(T x-x)+\left(1-t_{1} t_{2}\right)(T x-x) \\
& \quad=\left(1-t_{1} t_{2}+t_{1} t_{2} T^{\prime} \xi\right)(T x-x),
\end{aligned}
$$

where $\xi=x+\eta t_{1} t_{2}(T x-x), 0<\eta<1$. Therefore, if the derivative $T^{\prime}$ of $T$ satisfies

$$
\left|1-t_{1} t_{2}+t_{1} t_{2} T^{\prime} \xi\right|^{2} \leq \frac{\theta_{2}}{2}
$$

then

$$
\frac{\left\|T T_{t_{1}, t_{2} x} x-T_{t_{1}, t_{2}} x\right\|^{2}}{\|T x-x\|^{2}} \leq \frac{\theta_{2}}{2}, \quad \forall x \in C .
$$

In order to compare the convergence speeds and error estimations for Ishikawa iteration (1.1) and the Mann iteration, we consider the following example (the same as Example 2.1 in [6]) which satisfies all the conditions of Theorem 2.2.

Example 3.1 Let $C=[0.5,1.5]$ and define a mapping $T: C \rightarrow C$ by

$$
T x=-x+2+(x-1)^{3}, \quad x \in C .
$$

This real function is 1-Lipschitzian and strongly demicontractive with $a=0.15, K=0.42$ and $x^{*}=1$ is the unique fixed point of $T$. Set $\theta_{1}=0.2, \theta_{2}=0.5$. From

$$
\frac{1-\theta_{2}}{1-a} \leq t_{1} \leq \frac{1-\theta_{1}}{1-a}, \quad L^{2} t_{2}^{2}+t_{2}+a<1,
$$

we get $t_{1} \in[0.5882,0.9412]$ and $t_{2} \in[0,0.5488)$. We choose some $t_{1}$ and $t_{2}$ satisfying

$$
t_{1} t_{2} \in[0.4000,0.6154]
$$

Since

$$
T^{\prime} x=3(x-1)^{2}-1 \in\left[-1,-\frac{1}{4}\right], \quad \forall x \in C,
$$


we have

$$
\left|1-t_{1} t_{2}+t_{1} t_{2} T^{\prime} \xi\right|^{2} \leq\left(1-\frac{5}{4} t_{1} t_{2}\right)^{2} \leq \frac{\theta_{2}}{2} .
$$

Hence,

$$
\frac{\left\|T T_{t_{1}, t_{2}} x-T_{t_{1}, t_{2}} x\right\|^{2}}{\|T x-x\|^{2}} \leq \frac{\theta_{2}}{2}, \quad \forall x \in C .
$$

It can be seen that the conditions of Theorem 2.2 are satisfied.

(1) We first compare the convergence speed of Ishikawa iteration (1.1) with that of the Mann iteration. Let $t=0.6$ and $t=0.61$ (where $t \in[0.588,0.612]$ in [6]) in the Mann iteration. Let $t_{1}=0.8, t_{2}=0.5$ and $t_{1}=0.9, t_{2}=0.5$ in Ishikawa iteration (1.1). Set the stop parameter to $\left\|x_{n}-x^{*}\right\| \leq 10^{-15}$. Table 1 shows computation results for different initial points. Figure 1 gives 30 times calculating of CPU times for the iterations (see [9]).

From a mathematical point of view (Table 1), we see that Ishikawa iteration (iv) converges faster than the other three iterations. And convergence speeds of Mann iteration (i)

Table 1 Number of iterations required to obtain the fixed point $x^{*}=1$

\begin{tabular}{lllll}
\hline $\begin{array}{l}\text { Initial value } \\
x_{0}\end{array}$ & $\begin{array}{l}\text { (i) Mann iteration } \\
\text { for } t=0.6\end{array}$ & $\begin{array}{l}\text { (ii) Mann iteration } \\
\text { for } t=0.61\end{array}$ & $\begin{array}{l}\text { (iii) Ishikawa iteration } \\
\text { for } t_{1}=0.8 \text { and } \\
t_{2}=0.5\end{array}$ & $\begin{array}{l}\text { (iv) Ishikawa iteration } \\
\text { for } t_{1}=0.9 \text { and } \\
t_{2}=0.5\end{array}$ \\
\hline 0.5 & 22 & 23 & 22 & 15 \\
0.7 & 22 & 23 & 22 & 16 \\
0.9 & 22 & 23 & 21 & 15 \\
1.1 & 22 & 23 & 22 & 15 \\
1.3 & 22 & 23 & 22 & 16 \\
1.5 & 22 & 23 & 22 & 15 \\
\hline
\end{tabular}

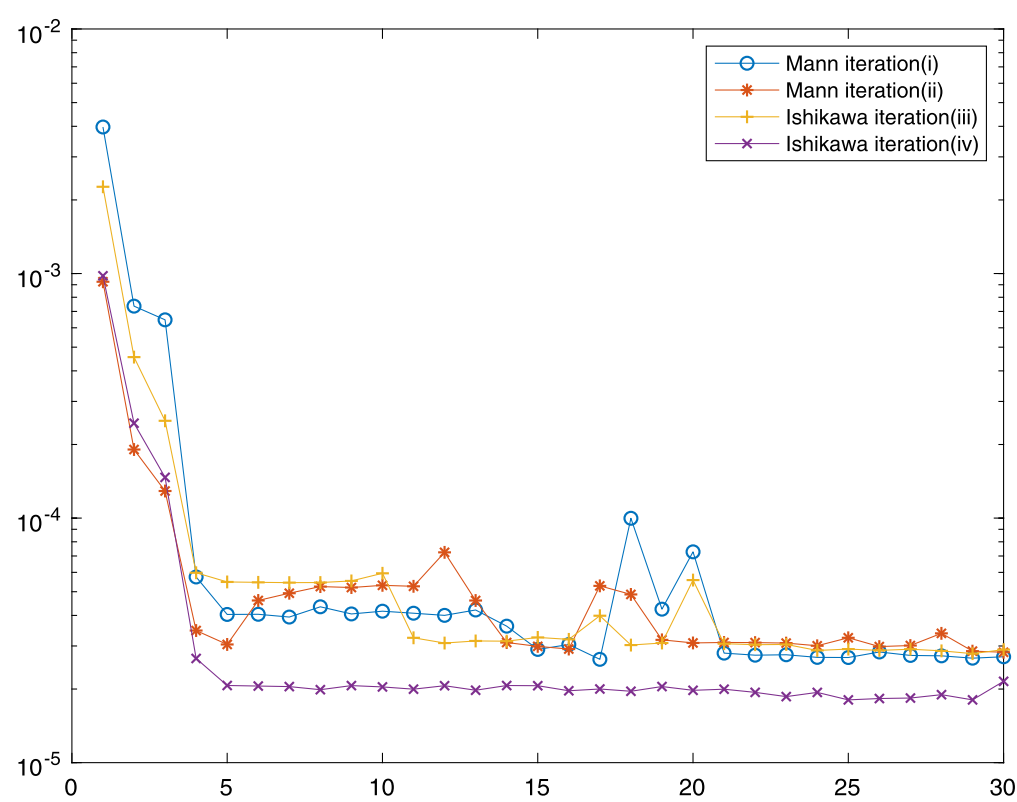

Figure 1 CPU time for Mann iterations and Ishikawa iterations with $x_{0}=0.5$ 


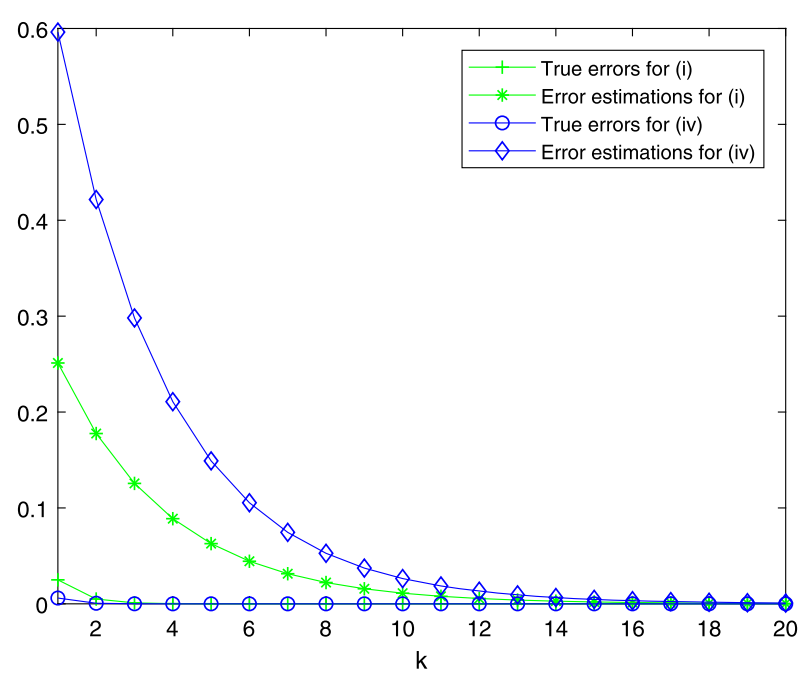

Figure 2 Illustration of true errors $\left\|x_{k}-x^{*}\right\|$ (see $1 \leq k \leq 20$ ) and error estimations for Mann iteration (i) and Ishikawa iteration (iv) with $x_{0}=0.5$

and Mann iteration (ii) are stable with respect to the given initial points. From a computercalculation point of view (Fig. 1), we also find that Ishikawa iteration (iv) converges faster than the other three iterations.

(2) And then, we want to compare the error estimation of Ishikawa iteration (1.1) with that of the Mann iteration (see (2.8) and (2.10)). Figure 2 shows the error estimations for Mann iteration (i) and Ishikawa iteration (iv). It can be found that the error estimation of Mann iteration (i) is more effective than the error estimation of Ishikawa iteration (iv).

\section{T-stability of the Ishikawa iteration for strongly demicontractive mappings}

Let $\left\{x_{n}\right\}$ be a sequence given by the iteration procedure

$$
x_{n+1}=f\left(T, x_{n}\right),
$$

where $T: X \rightarrow X$ and $x_{0} \in X$.

Generally speaking, a fixed point iteration procedure is called stable if small modifications in the initial data that are involved in the computation process produce a small influence on the computed value of the fixed point. Now, we give the specific definition of stability for the iteration procedure as follows.

Definition 4.1 ([2]) Let $(X, d)$ be a metric space and $T: X \rightarrow X$ be a mapping, $x_{0} \in X$ and the sequence $\left\{x_{n}\right\}$ produced by (4.1) converges to a fixed point $x^{*}$ of $T$. Let $\left\{z_{n}\right\}$ be an arbitrary sequence in $X$ and set

$$
\varepsilon_{n}=d\left(z_{n+1}, f\left(T, z_{n}\right)\right) \quad \text { for } n=0,1,2, \ldots
$$

We shall say that the fixed point iteration procedure (4.1) is T-stable or stable with respect to $T$ if only if

$$
\lim _{n \rightarrow \infty} \epsilon_{n}=0 \Longleftrightarrow \lim _{n \rightarrow \infty} z_{n}=x^{*} .
$$


Under the same assumptions in [4], we will prove that the Ishikawa iteration is also Tstable for strongly demicontractive mappings.

Theorem 4.1 Let $T$ be strongly demicontractive with $K \in[0,1)$ and $x^{*} \in \operatorname{Fix}(T)$. For $x_{0} \in$ $C$, let $\left\{x_{n}\right\}$ be the sequence generated by Ishikawa iteration (1.1) with the control sequence $\lambda \leq \alpha_{n}<1$ for some $\lambda>0$. Assume that

$$
a+\frac{4 K}{(1-K)^{2}}<1
$$

Then $\left\{x_{n}\right\}$ converges strongly to $x^{*}$ and Ishikawa iteration (1.1) is stable with respect to T.

Proof From the proof of Theorem 2 in [4], we have

$$
\left\|T x-x^{*}\right\| \leq M\left\|x-x^{*}\right\|
$$

where $M=\sqrt{a+\frac{4 K}{(1-K)^{2}}}<1$. Suppose that $\left\{z_{n}\right\}$ is a sequence in $C$. Define

$$
\epsilon_{n}=\left\|z_{n+1}-\left(1-\alpha_{n}\right) z_{n}-\alpha_{n} T s_{n}\right\|
$$

and

$$
s_{n}=\left(1-\beta_{n}\right) z_{n}+\beta_{n} T z_{n},
$$

we have

$$
\begin{aligned}
\left\|z_{n+1}-x^{*}\right\| & \leq\left\|\left(1-\alpha_{n}\right) z_{n}-x^{*}+\alpha_{n} T s_{n}\right\|+\left\|z_{n+1}-\left(1-\alpha_{n}\right) z_{n}-\alpha_{n} T s_{n}\right\| \\
& \leq\left(1-\alpha_{n}\right)\left\|z_{n}-x^{*}\right\|+\alpha_{n}\left\|T s_{n}-x^{*}\right\|+\epsilon_{n} \\
& \leq\left[1-\alpha_{n}+\alpha_{n}\left(1-\beta_{n}\right) M+\alpha_{n} \beta_{n} M^{2}\right]\left\|z_{n}-x^{*}\right\|+\epsilon_{n} \\
& \leq\left[1-\alpha_{n}+\alpha_{n}\left(1-\beta_{n}\right) M+\alpha_{n} \beta_{n} M\right]\left\|z_{n}-x^{*}\right\|+\epsilon_{n} \\
& \leq\left(1-\alpha_{n}+\alpha_{n} M\right)\left\|z_{n}-x^{*}\right\|+\epsilon_{n} .
\end{aligned}
$$

Now, let $\alpha=1-\lambda+\lambda M$, where $\lambda=\frac{1-\theta_{2}}{1-a}$. Since $0<M<1$, we have $0<\alpha<1$ and

$$
1-\alpha_{n}+\alpha_{n} M \leq \alpha
$$

Therefore,

$$
\left\|z_{n+1}-x^{*}\right\| \leq \alpha\left\|z_{n}-x^{*}\right\|+\epsilon_{n}
$$

If $\lim _{n \rightarrow \infty} \epsilon_{n}=0$, then it follows by Lemma 1.1 that $\lim _{n \rightarrow \infty} z_{n}=x^{*}$. Since

$$
\left\|x_{n+1}-\left(1-\alpha_{n}\right) x_{n}-\alpha_{n} T y_{n}\right\|=0,
$$


it also results in $\lim _{n \rightarrow \infty} x_{n}=x^{*}$, i.e., $\left\{x_{n}\right\}$ converges strongly to $x^{*}$. Conversely, suppose $\lim _{n \rightarrow \infty} z_{n}=x^{*}$. It follows from

$$
\epsilon_{n} \leq\left\|z_{n+1}-x^{*}\right\|+\left(1-\alpha_{n}\right)\left\|z_{n+1}-x^{*}\right\|+\alpha_{n}\left\|T s_{n}-x^{*}\right\|
$$

that $\lim _{n \rightarrow \infty} \epsilon_{n}=0$. Hence, Ishikawa iteration (1.1) is stable with respect to $T$.

Remark 4.1 (1) Theorem 4.1 extends the corresponding results of [4] (Theorem 2 of [4]) into the case of the Ishikawa iteration. In order to guarantee that $0<\alpha<1$, the condition " $a+\frac{4 K}{(1-K)^{2}} \leq 1$ " (Theorem 2 of [4]) should be " $a+\frac{4 K}{(1-K)^{2}}<1$ ".

(2) Theorem 4.1 gives anthor convergence theorem for the strongly demicontractive mapping $T$ with condition (4.2). As we know, condition (4.2) is relatively strong. Indeed, the condition implies that $0<K<3-\sqrt{8}$.

(3) In Example 3.1, condition (4.2) does not hold. But we know that

$$
\left\|T x-x^{*}\right\| \leq \frac{3}{4}\left\|x-x^{*}\right\| .
$$

From the proof of Theorem 4.1, the Mann iteration and the Ishikawa iteration are still T-stable when the control sequence $\lambda \leq \alpha_{n}<1$ for some $\lambda>0$.

Example 4.1 Let $C=[-1,1]$ and define a mapping $f: C \rightarrow C$ by

$$
f(x)= \begin{cases}0.6 x, & x \in\left[-1, \frac{1}{2}\right] \\ -x+0.4, & x \in\left(\frac{1}{2}, 1\right] .\end{cases}
$$

This real function is strongly demicontractive with $a=0.35, K=0.1$, and $a+\frac{4 K}{(1-K)^{2}} \approx$ $0.84<1$.

Now, we consider the Mann iterations and the Ishikawa iterations (in Example 3.1) for the above function. Theorem 4.1 shows that the sequences generated by these iterations converge strongly to the fixed point $x^{*}=0$ and all these iterations are stable with respect to $f(x)$. Also set the stop parameter to $\left\|x_{n}-x^{*}\right\| \leq 10^{-15}$. From Table 2 (Number of iterations) and Fig. 3 (CPU time), we know that Ishikawa iteration (iv) converges faster than the other three iterations.

\section{Conclusion}

In this paper, we have developed some convergence theorems and T-stability of the Ishikawa iteration for strongly demicontractive mappings. By finding fixed points of some

Table 2 Number of iterations required to obtain the fixed point $x^{*}=0$

\begin{tabular}{lllll}
\hline $\begin{array}{l}\text { Initial value } \\
x_{0}\end{array}$ & $\begin{array}{l}\text { (i) Mann iteration } \\
\text { for } t=0.6\end{array}$ & $\begin{array}{l}\text { (ii) Mann iteration } \\
\text { for } t=0.61\end{array}$ & $\begin{array}{l}\text { (iii) Ishikawa iteration } \\
\text { for } t_{1}=0.8 \text { and } \\
t_{2}=0.5\end{array}$ & $\begin{array}{l}\text { (iv) Ishikawa iteration } \\
\text { for } t_{1}=0.9 \text { and } \\
t_{2}=0.5\end{array}$ \\
\hline 0.8 & 119 & 116 & 64 & 55 \\
0.5 & 121 & 119 & 64 & 54 \\
0.2 & 121 & 119 & 63 & 54 \\
-0.2 & 121 & 119 & 63 & 54 \\
-0.5 & 125 & 123 & 64 & 55 \\
-0.8 & 127 & 124 & 65 & 56 \\
\hline
\end{tabular}




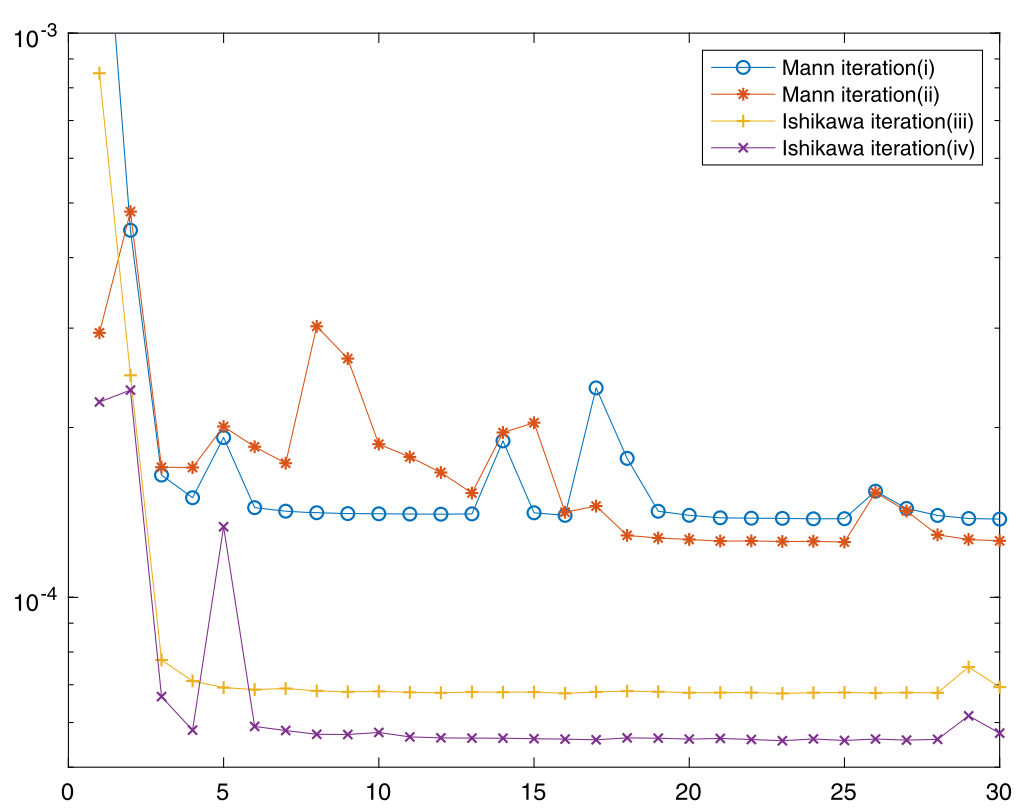

Figure $3 \mathrm{CPU}$ time for Mann iterations and Ishikawa iterations with $x_{0}=0.5$

strongly demicontractive mappings (see Example 3.1 and Example 4.1), we show that the Ishikawa iteration converges faster than the Mann iteration (see Tables 1-2, Fig. 1 and Fig. 3), but the Mann iteration is more efficient for the error estimation (see Fig. 2).

\section{Acknowledgements}

The authors thank the editor and the referees for constructive and pertinent suggestions.

\section{Funding}

This paper was partially supported by the NSF of China (No. 11126290 and No. 61573192), University Science Research Project of Jiangsu Province (No. 13KJB1 10021), and Scholarship Award for Excellent Doctoral Student granted by the Ministry of Education (No. 1390219098).

\section{Competing interests}

The authors declare that they have no competing interests.

\section{Authors' contributions}

Each of the authors contributed to each part of this study equally, all authors read and approved the final manuscript

\section{Author details}

'School of Mathematics and Statistics, Nanjing University of Information Science and Technology, Nanjing, P.R. China.

${ }^{2}$ Reading Academy, Nanjing University of Information Science and Technology, Nanjing, P.R. China.

\section{Publisher's Note}

Springer Nature remains neutral with regard to jurisdictional claims in published maps and institutional affiliations.

Received: 9 December 2018 Accepted: 18 March 2019 Published online: 25 March 2019

\section{References}

1. Liu, L.W.: Approximation of fixed points of a strictly pseudocontractive mapping. Proc. Am. Math. Soc. 125, 1363-1366 (1997)

2. Berinde, V.: Iterative Approximation of Fixed Points. Lecture Notes in Mathematics. Springer, Berlin (2007)

3. Ciric, L.B., Rafiq, A., Radenovic, S., Rajovic, M., Ume, J.S.: On Mann implicit iteration for strongly accretive and strongly pseudo-contractive mappings. Appl. Math. Comput. 198, 128-137 (2008)

4. Maruster, L., Maruster, St:. On the error estimation and T-stability of the Mann iteration. J. Comput. Appl. Math. 276, 110-116 (2015)

5. Maruster, St., Rus, I.A.: Kannan contractions and strongly demicontractive mappings. Creative Math. Inform. 24, $171-180(2015)$ 
6. Wang, C.: A note on the error estimation of the Mann iteration. J. Comput. Appl. Math. 285, 226-229 (2015)

7. Rezapour, S., Haghi, R.H., Rhoades, B.E.: Some results about T-stability and almost T-stability. Fixed Point Theory 12 179-186 (2011)

8. Haghi, R.H., Postolache, M., Rezapour, S.: On T-stability of the Picard iteration for generalized $\varphi$-contraction mappings. Abstr. Appl. Anal. 2012, Article ID 658971 (2012)

9. Fathollahi, S., Ghiura, A., Postolache, M., Rezapour, S.: A comparative study on the convergence rate of some iteration methods involving contractive mapping. Fixed Point Theory Appl. 2015, 234 (2015)

10. Fathollahi, S., Rezapour, S.: Efficacy of coefficients on rate of convergence of some iteration methods for quasi-contractions. Iran. J. Sci. Technol., Trans. A, Sci. 42, 1517-1523 (2018)

\section{Submit your manuscript to a SpringerOpen ${ }^{\circ}$} journal and benefit from:

- Convenient online submission

- Rigorous peer review

- Open access: articles freely available online

- High visibility within the field

- Retaining the copyright to your article

Submit your next manuscript at $\gg$ springeropen.com 